J. BRAUN, M. ŠTRONER, R. URBAN

\section{EXTENSIVE TESTING AND COMPARISON OF A NEW TYPE OF TARGET FOR USE IN ENGINEERING SURVEYING}

\begin{abstract}
The paper deals with the testing of a special target for determining the exact dimensions of steel structures and their descriptions. In most cases, the accuracy required in mechanical engineering is on the order of millimetres, and the location of a point on a steel construction is marked by a centre punch. Due to the segmentation of steel constructions and the impossibility of the vertical placement of a target, it is very difficult to use ordinary prisms because of their size and the linear error from a wrong rotation and a nontrivial conversion of the centre of a prism into a centre punch on a steel construction. For a more accurate determination of spatial coordinates, a special reflective target with a reflective foil and a mechanical collimator, which ensures the correct angle to the target device according to the instructions of the person at the instrument, has been developed. Centration with a high degree of accuracy is achieved by a spike. Its functionality and usability goals have been tested and compared with standard methods of measurements and goals in engineering structures.
\end{abstract}

Jaroslav Braun
Email: jaroslav.braun@fsv.cvut.cz
Research field: Engineering surveying.
Martin Štroner
Email: martin.stroner@fsv.cvut.cz
Research field: Engineering surveying,
adjustment of geodetic networks, laser
scanning, optimization of geodetic
measurement, geodetic software .
Rudolf Urban
Email: rudolf.urban@fsv.cvut.cz
Research field: Engineering surveying,
photogrammetry, geodetic software.
Address: Department of Special geodesy
Faculty of Civil Engineering, Czech technical
university in Prague, Thákurova 7, Prague 6,
16629 Prague.

\section{KEY WORDS}

- Reflective target,

- collimator,

- test,

- measurement of steel constructions,

- engineering surveying.

\section{INTRODUCTION}

The measurement of shapes and dimensions of large segments of steel constructions is one of the goals of engineering surveying, where the required standard deviations of control measurements range in the order of millimetres, and reaching them is not a trivial matter. The measurements are performed directly in production plants or on site, where surveillance is important not only to identify the conformity of a specific part with the project, but, in particular, for its compatibility with other parts of the construction. The inspection is usually performed by the geodetic measurement of the respective points, which are usually marked by a centre punch on the construction using the polar method. Today's top-performance surveying instruments used for such control measurements reach standard deviations in the determination of the direction of up to 0.15 mgon and a distance of $0.5 \mathrm{~mm}$ (e.g., the Leica TDM 5005). To achieve such a degree of accuracy, the measurements must be made with utmost care, and the corresponding equipment and site conditions must be provided. A high degree of accuracy in angular measurements may be achieved by a suitable positioning of the instrument and by securing good visibility in the direction of the measured construction, but to reach a high degree of accuracy in distance measurement, an appropriate reflective target is also necessary, as incorrectly choosing it or the incorrect rotation of the reflective surface with respect to the instrument may cause an error of up to several millimetres in magnitude. Since steel constructions are generally of large dimensions and versatile shapes, a wide variety of reflective targets, such as glass prisms, reflective sheet targets 


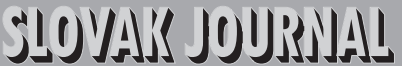 \\ 1) $\overrightarrow{5}$

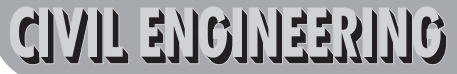

Vol. XXI, 2013, No. 2, $29-40$

and special fixtures, may be used for measurement, although each of these reflective targets has its positive and negative features. In addition to standard equipment, there are special tools (Prokop, 2009) and a variety of industrially produced targets available on the market, but they are very expensive.

The objective of this paper is to present a target with a reflective foil and mechanical collimator, which was developed at the Department of Special Geodesy of the Faculty of Civil Engineering, CTU in Prague, and which should allow for the universal measurement of distances to points of steel constructions with the control of the correct rotation by means of a collimator and correct centration by a sharp spike. The text below describes the targets used for the length measurements and the procedures for testing it. The testing is supposed to verify its suitability and the applicability of the new target for measurements and compare it with other targets commonly used for the measurement of steel constructions. Another aim of the testing is to verify the versatility of the instrument used with total stations with different types of distance meters and with variable sizes of the effective traces of the distance meter.

\section{TARGETS FOR DISTANCE MEASUREMENTS}

The targets selected for the verification test of their suitability for the measurement of steel constructions and for mutual comparisons were the Leica GMP111 mini prism, a reflective sheet target, a rod with two offset reflective foils and a target with a reflective foil and mechanical collimator. All the reflective foils used were manufactured by the Sokkia Company and have dimensions of $30 \times 30 \mathrm{~mm}(\mathrm{RS} 30 \mathrm{~N}$ type $)$.

\subsection{Leica GMP111 mini prism}

The standard application of mini prisms is with a centring rod and a box level (Fig. 1) by means of which they are vertically

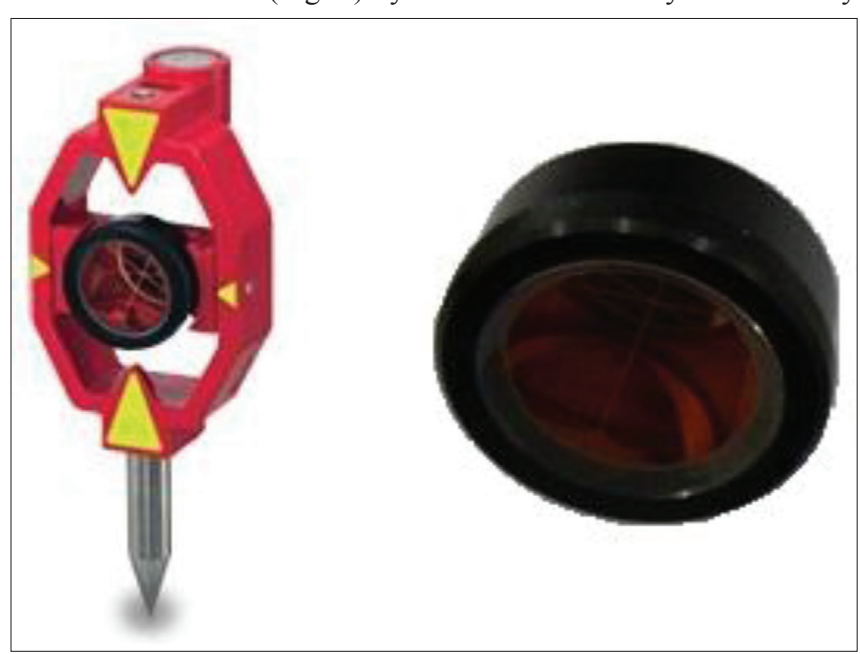

Fig. 1 Leica GMP111 mini prism. aligned above a point. The segmentation of a steel construction, however, frequently does not permit such a positioning, so the prism may be screwed out of the case with a level and used separately. In such a case, it is necessary to determine the additive constant of the prism with respect to the tip of the rear spike, which is placed on the centre punch on the construction. Despite this adjustment, the measurement with a mini prism may be problematic due to its dimensions, where at some points the spike cannot be placed on the point and the prism simultaneously targeted onto the instrument. A disadvantage is the impossibility of checking the prism's rotation with respect to the instrument and also the necessity of separate distance and angular measurements where the distance is measured first, while the horizontal direction and the zenith angle to the centre punch are only measured after the removal of the prism.

\subsection{Reflective sheet target}

With their size and thin cross sections, reflective sheet targets compensate for the disadvantage of the large dimensions of a prism (Fig. 2). Halves of reflective foils are usually used for measurement so that the centre of the reticle is placed directly on the measured point. An advantage is the possibility of the immediate measurement of distances and angles in the case of targeting exactly onto a centre punch. They may be expediently used mainly for the measurement of points on surfaces perpendicular to the sight line of the instrument. At other points, however, the impossibility of checking the rotation of the reflective surface perpendicular to the instrument becomes an obstacle as well as the uncertainty of the correct centration above the center punch.

\subsection{Engineering fixtures}

Professionally produced fixtures for the measurement of steel constructions take many forms; the most frequently used type is a magnetically fastened rectangular shape that fits in the given type

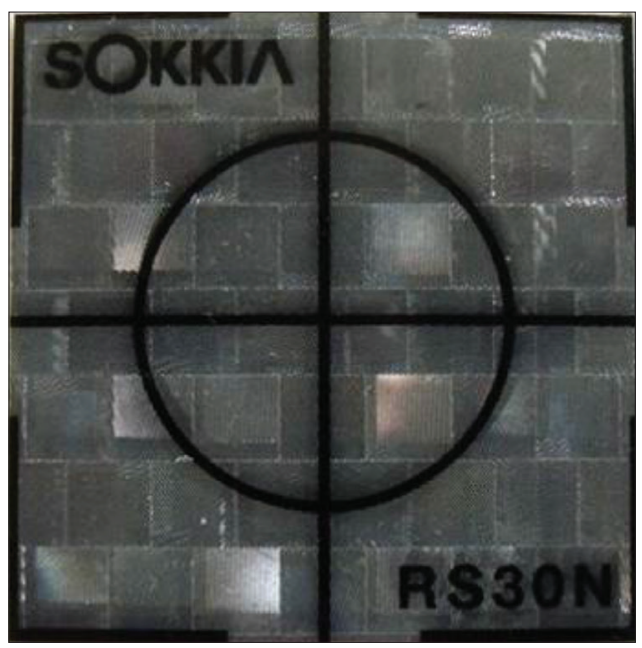

Fig. 2 Reflective foil. 


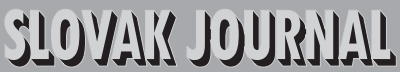 \\ 1) $\mathrm{s}^{3}$

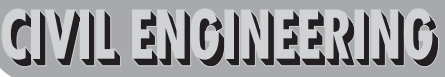

Vol. XXI, 2013, No. 2, $29-40$

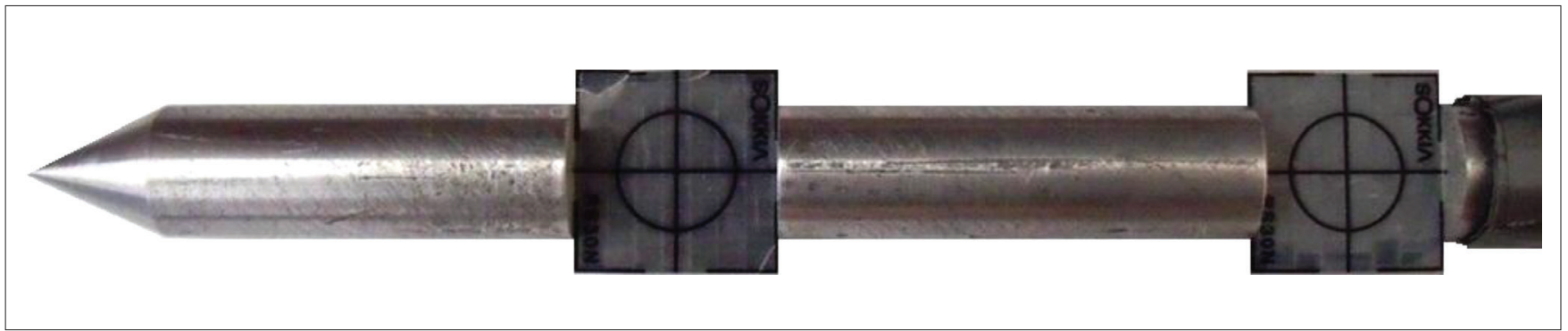

Fig. 3 Rod with reflective foils.

of construction or fixtures allowing for the measurement of the covered points where these points are identified indirectly via other precisely measured points. A bar with two reflective foils was used for the testing purposes (Fig. 3), where the offset between the spike and the centre of the foil 1 is $100 \mathrm{~mm}$, and the offset between the centre of foils 1 and 2 is $100 \mathrm{~mm}$. The drawback of such fixtures may be their high cost, the impossibility of checking their rotation, and also the fact that the coordinates of the resultant point are identified indirectly via the other measured points.

\subsection{Target with a reflective foil and mechanical collimator}

This type of target is a fixture produced at the Department of Special Geodesy of the Faculty of Civil Engineering, CTU in Prague, which was developed on the basis of experience gained and problems arising in the measurement of steel constructions. With its characteristic simplicity and low cost, it should compensate for the majority of the drawbacks associated with the reflective targets above. Its principal advantages are the possibility of checking the rotation of the fixture with respect to the instrument, so that the reflective surface is perpendicular to the telescope (distance meter) axis and is precisly centred on the centre punch by means of a sharp spike.

\subsubsection{Target description}

The target is a metal plate with dimensions of $30 \times 30 \mathrm{~mm}$ with reflective foil on its front onto which a metal spike $5 \mathrm{~mm}$ in length is fixed so that its axis is identical to the front side of the reflective foil and its vertical axis. A mechanical collimator is fastened to its upper edge; the collimator is composed of two plates with dimensions of $10 \times 10 \mathrm{~mm}$ mounted perpendicular to each other, so that they form a cross when the foil is viewed from the front. The collimator plates are mounted perpendicular to the foil surface. The collimator surfaces differ by colour so that the operator of the instrument may better distinguish when the target is rotated directly perpendicular to the sight line (Fig. 4). The target dimensions may be larger or smaller, depending on the measured distance and also to ensure comfortable targeting. The mechanical collimator may be complemented or replaced by a laser (Fig. 5), where the laser axis must be exactly adjusted so that it is perpendicular to the reflective surface; and the laser must be chosen so as to avoid eye damage due to the accidental exposure of the operator's eye to the laser beam. This layout makes the target rotation easier where the lineman rotates the target so that the laser spot falls onto a previously identified point on the telescope.

The only disadvantage of a target with a reflective foil and mechanical collimator is that it does not permit measurement of points which are situated on a surface perpendicular to the telescope's line of sight. This drawback, however, may be compensated for by a suitable choice of a station for measurement.

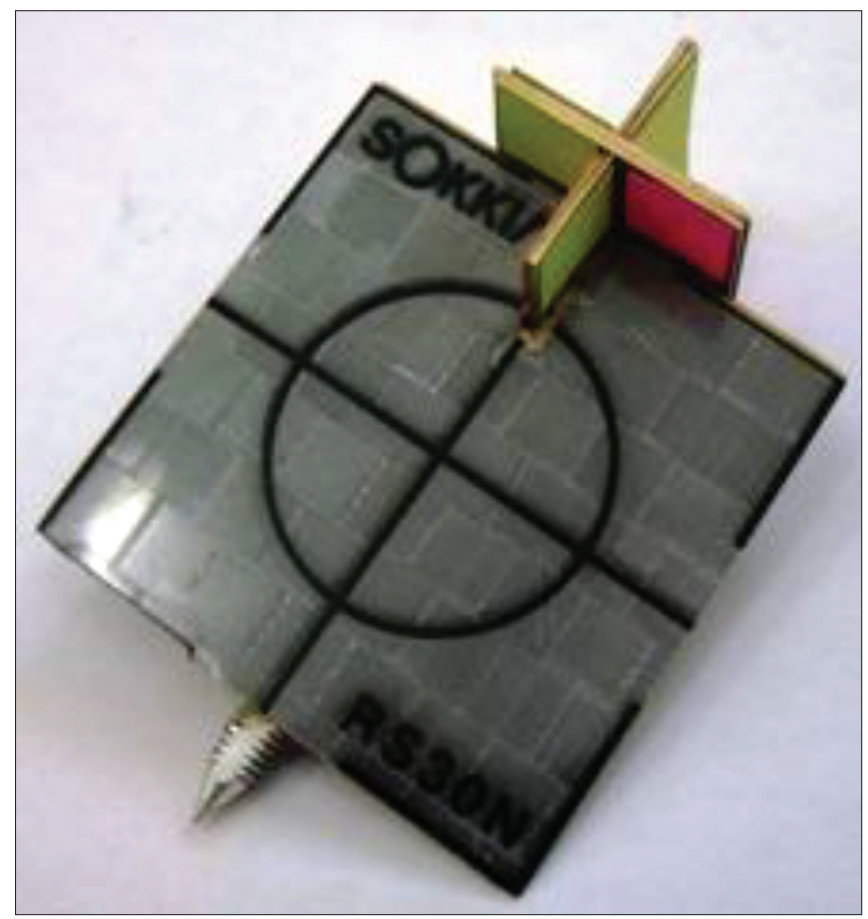

Fig. 4 Target with a reflective foil and mechanical collimator. 


\section{IIIJ) \\ 1) 5

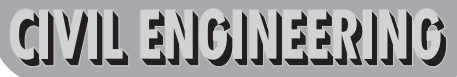

Vol. XXI, 2013, No. 2, $29-40$

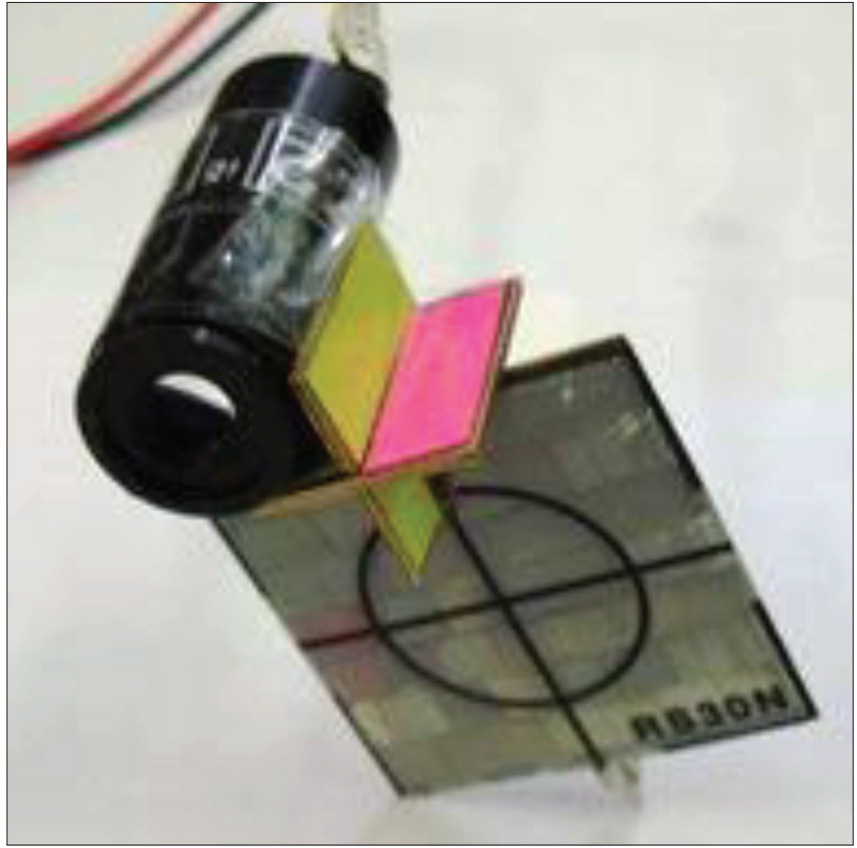

Fig. 5 Target with laser.

\subsubsection{Measurement procedure of a target with a reflective foil and mechanical collimator}

The target is designed so that the lineman may place the spike into the centre punch on the construction and, by means of the instrument operator's instructions, align the target in such a position that the operator can only see the collimator cross and not its surfaces; this is also enhanced by the colour distinction of the individual surfaces. At the moment when only the collimator cross is visible, the foil surface is perpendicular to the sight line of the telescope, and the distance measurement may be performed. After the distance is measured, retargeting onto the tip of the spike must be performed and the horizontal direction and zenith angle registered. For this step, it must be pointed out that the option of recalculating the measured distance with respect to the vertical angular offset magnitude must be switched off as the target is not vertically aligned as is in the case of commonly used mini prisms, so the recalculation may produce a distortion in the measured distance amounting up to several millimetres. Measurement onto a target with a reflective foil and collimator is schematically displayed in Fig. 6.

Since the target centre (and not the centre punch directly) is targeted during the measurement, a slight distance error $\Delta$ arises, which is calculated for different sight line lengths in Tab. 1 based on the Pythagorean theorem.

$$
\begin{aligned}
& l=\sqrt{s^{2}+h^{2}}, \\
& \Delta=l-s .
\end{aligned}
$$

The magnitude of the error $\Delta$ with respect to the actual accuracy rates of the distance meters is negligible for the majority of the distances, and it need not be numerically eliminated.

\section{TESTING MEASUREMENT FOR VERIFICATION OF THE SUITABILITY OF THE MEASUREMENT OF STEEL CONSTRUCTIONS}

The site selected for the test of the verification of the suitability of the target with a reflective foil and mechanical collimator for measurement on steel constructions and its comparison with the other targets was the laboratory space in building $\mathrm{C}$ of the Faculty of Civil Engineering, CTU in Prague, where 10 points were established in

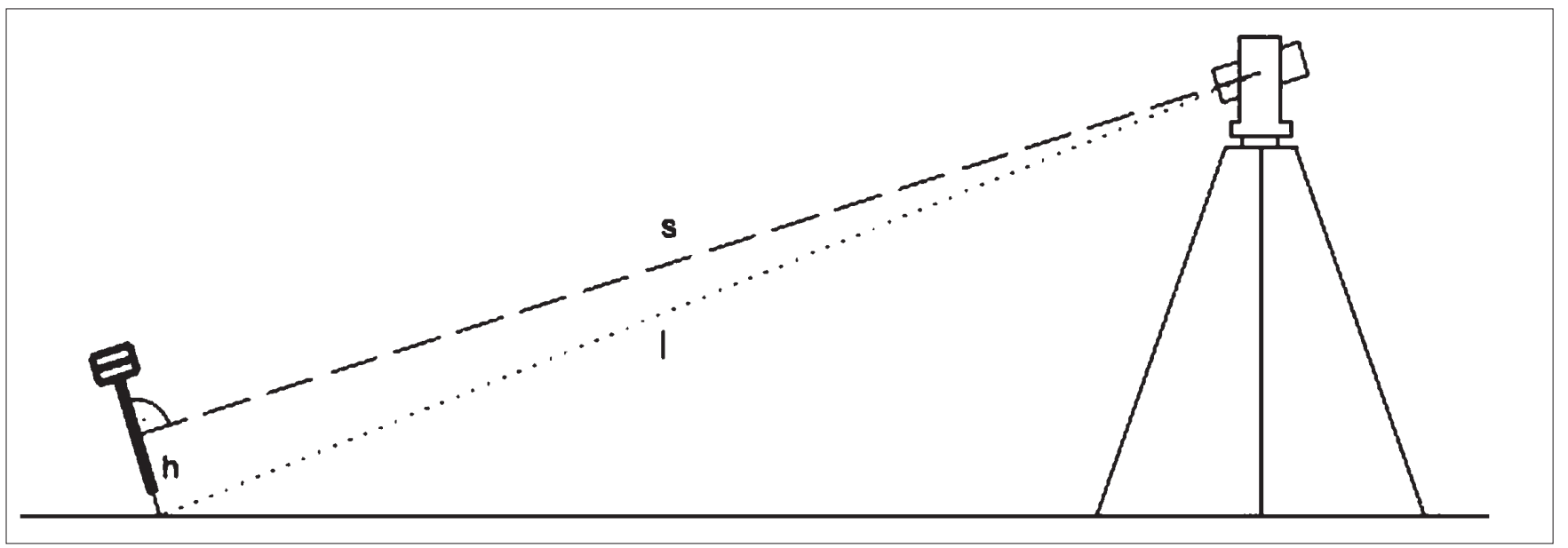

Fig. 6 Measurement onto a target with a reflective foil and collimator. 
Vol. XXI, 2013, No. 2, $29-40$

Tab. 1 Distance error due to targeting onto target centre instead of centre punch ( $h=20 \mathrm{~mm})$.

\begin{tabular}{|l|r|r|r|r|r|r|r|r|r|}
\hline Measured distance $s[\mathrm{~m}]$ & 2.00000 & 3.00000 & 4.00000 & 5.00000 & 7.50000 & 10.00000 & 12.50000 & 15.00000 & 20.00000 \\
\hline Correct length $l[\mathrm{~m}]$ & 2.00010 & 3.00007 & 4.00005 & 5.00004 & 7.50003 & 10.00002 & 12.50002 & 15.00001 & 20.00001 \\
\hline Error $\Delta[\mathrm{mm}]$ & 0.10 & 0.07 & 0.05 & 0.04 & 0.03 & 0.02 & 0.02 & 0.01 & 0.01 \\
\hline
\end{tabular}

space (on the floor and on the walls) to simulate a steel construction The points were stabilised by stickers with a cross (Fig. 7). The aim of the test was to obtain the standard deviations characterizing the individual reflective targets when comparing the reference and measured distances and coordinates.

The measurement was performed using the Trimble S6 HP instrument $\left(\sigma_{\varphi}=0.3\right.$ mgon, $\sigma_{D}=1 \mathrm{~mm}+1 \mathrm{ppm} \mathrm{D}-$ see (ČSN ISO $17123,2005))$, which fully complies with the requirements for the measurement of steel constructions by its accuracy (Fig. 10).

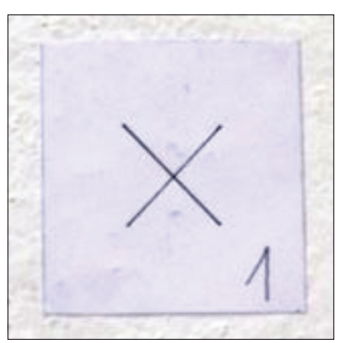

Fig. 7 Detailed survey point.

\subsection{Reference micro network}

A reference coordinate system had to be introduced for the potential mutual comparison of the targets and the coordinates of the measurement stations, and the reference coordinates of the 10 detailed survey points representing a steel construction had to be identified.

Three stations (4001, 4002 and 4003) stabilised by tripods were selected in the laboratory as far as possible from the detailed survey points. Furthermore, a tripod with a $2 \mathrm{~m}$ standardised basemeasuring Bala rod, which was selected for the identification of the network dimensions (translation method principle), was mounted in the space among the detailed survey points. The diagram of the reference network is in Fig. 8.

The measurement of the horizontal directions and zenith angles in the two groups to all the detailed survey points and to both ends of the base measuring rod and the measurement of the horizontal directions, zenith angles and slope distances in the two groups to the other station points was performed from each station. The target

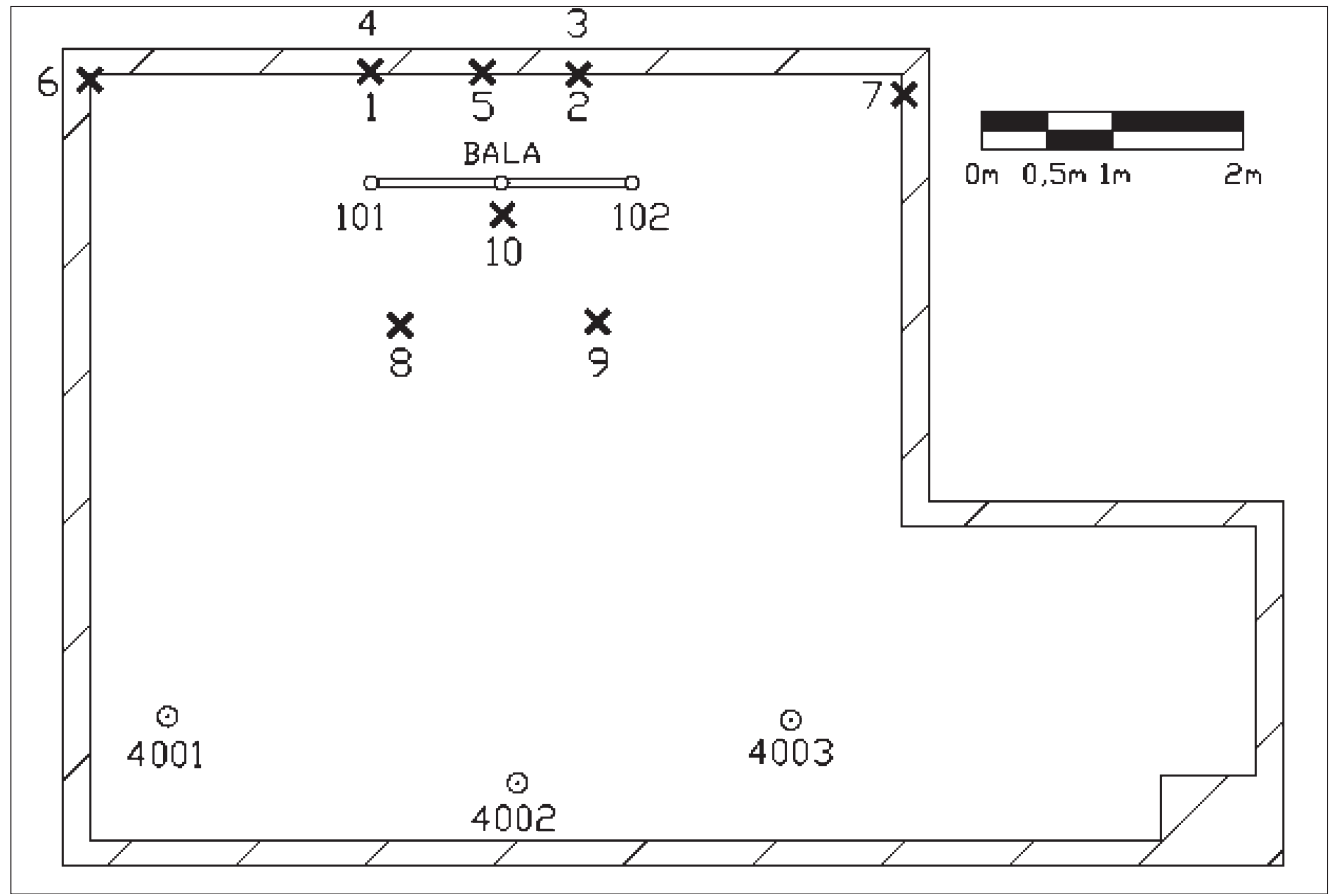

Fig. 8 Micro network diagram for verification of the suitability of the target.

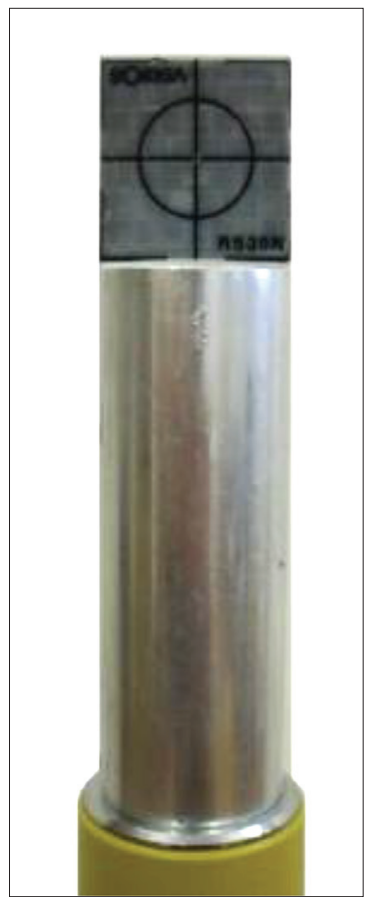

Fig. 9 Target on the station. 
Vol. XXI, 2013, No. 2, $29-40$

selected for the station was the fixture with a foil, which guarantees accurate centring and the same height as that of the trunnion axis of the telescope of the Trimble S6 HP instrument (Fig. 9).

\subsection{Measurement of the detailed survey points}

After the measurement of the two groups in the micro network, the measurement of the selected reflective targets and points was gradually performed from each station. The measurement included horizontal directions, zenith angles and slope distances in one group. The targets were settled as accurately as possible. The measurement of all the targets was performed identically to be able to mutually compare them. The new tested target with a reflective foil and mechanical collimator was measured twice from each station. The first measurement was made with utmost care, where the operator gave instructions to the lineman to rotate the target surfaces. The second measurement was made without any operator instructions, and its objective was to identify the magnitude of an error due to the incorrect rotation of the target where the lineman held and rotated the target only at his own discretion. The list of the measured points and targets used is in Tab. 2.

\section{MEASUREMENT PROCESSING}

\subsection{Micro network computation}

The coordinates of the points of the micro network were computed by adjustment using the least squares method in the GNU Gama programme (Čepek, 2012), which permits defining the input data set for adjustment in a simple file in the xml (Extensible Markup Language) format. The option of entering various standard deviations of the measurement of the individual variables entering the adjustment (horizontal directions, zenith angles and distances) is of essential importance. Due to the short sight line lengths, the standard deviations of the measurement of the horizontal directions and zenith angles selected for group 1 were 1 mgon (for sight lines shorter than $3 \mathrm{~m}$, the standard deviations selected were $2 \mathrm{mgon}$ ), while the standard deviation selected for the distance measurement was $1 \mathrm{~mm}$, as declared by the manufacturer of the instrument. The points of the base measuring Bala rod were selected as fixed points where the standardised length of the rod was used for the identification of the network dimensions.

Forty-two horizontal directions, 42 zenith angles and 6 slope distances were measured in the micro network from 3 standpoints. The number of unknown variables was identified as 43 (XYZ coordinates of 13 points, the $\mathrm{Z}$ coordinate of one point of the base measuring rod, and 3 orientation shifts). No outliers were identified in the 47 redundant measurements; therefore, all 90 observations were used for the computation. The fixed $\mathrm{XYZ}$ coordinates $(\mathrm{X}=$ $500 \mathrm{~m} ; \mathrm{Y}=100 \mathrm{~m} ; \mathrm{Z}=100 \mathrm{~m}$ ) were entered into point 101 (the left end of the base measuring Bala rod), and the fixed $\mathrm{XY}$ coordinates $(X=500 \mathrm{~m} ; \mathrm{Y}=102 \mathrm{~m}$ ) were entered into point 102 (the right end of the base measuring Bala rod). The measured variables were averaged before adjustment and, depending on the number of repetitions, they were assigned the respective standard deviation using the formula:

$$
\sigma_{i}=\frac{\sigma_{0}}{\sqrt{n}}
$$

where $\sigma_{\mathrm{i}}$ is the a priori standard deviation of a measured variable; $\sigma_{0}$ is the a priori standard deviation due to the instrument's accuracy reflecting the conditions during the measurement, and $n$ is the number of repetitions.

The degree of accuracy achieved in the identification of the rectangular spatial coordinates of the points in the micro network is expressed by the values of the standard deviations in the positioning of the individual points. Several indicators were selected for the description of the results of the adjustment:

The maximum standard deviation in the position is $0.3 \mathrm{~mm}$. The minimum standard deviation in the position is $0.1 \mathrm{~mm}$.

The mean standard deviation in the position is $0.2 \mathrm{~mm}$.

\subsubsection{Assessment of the adjustment results}

It is advisable to make a general assessment following the adjustment as to whether the degree of accuracy corresponds to the degree of accuracy planned during the accuracy analysis before the measurement by assessing the agreement of the standard deviations characterising the accuracy of the measurements entered into the weight for the adjustment with corrections. There

Tab. 2 Tested targets and measured detailed survey points.

\begin{tabular}{|c|c|c|c|c|c|}
\hline \multirow{2}{*}{ Target / Station } & \multicolumn{5}{|c|}{ Measured points } \\
\cline { 2 - 6 } & $\begin{array}{c}\text { Target with } \\
\text { collimator } \\
\text { (rotated) }\end{array}$ & $\begin{array}{c}\text { Target with } \\
\text { collimator } \\
\text { (non-rotated) }\end{array}$ & $\begin{array}{c}\text { Reflective sheet } \\
\text { target }\end{array}$ & Leica mini prism & $\begin{array}{c}\text { Rod with two } \\
\text { reflective foils }\end{array}$ \\
\hline 4001 & $1-10$ & $1-10$ & $1-10$ & $1-5$ & $8-10$ \\
\hline 4002 & $6-10$ & $6-10$ & $1-10$ & $1-5$ & $8-10$ \\
\hline 4003 & $1-10$ & $1-10$ & $1-10$ & $1-5$ & $8-10$ \\
\hline
\end{tabular}


is a simple procedure for the testing of the unit standard deviation after adjustment (a posteriori) $s_{0}$ against the a priori unit standard deviation used for the selection of the weight applying the limit sample standard deviation (see (Štroner, Hampacher, 2011)). The limit sample standard deviation:

$$
s_{M}=\sigma_{0} \cdot\left(1+\sqrt{\frac{2}{n^{\prime}}}\right),
$$

where $\sigma_{0}$ is the a priori standard deviation used for the weight formation; $n$ ' is the number of redundant variables. The a posterior standard deviation is identified as:

$$
s_{0}=\sqrt{\frac{\boldsymbol{v}^{T} \cdot \boldsymbol{P} \cdot \boldsymbol{v}}{n^{\prime}}},
$$

where $\boldsymbol{v}$ is the correction vector after adjustment; $\boldsymbol{P}$ is (here) the diagonal weight matrix; and the weight $p_{i}$ for individual measurements knowing their standard deviations $\sigma_{\mathrm{i}}$ is identified from the formula:

$$
p_{i}=\frac{c}{\sigma_{i}^{2}}
$$

where $c$ is the constant selected.

The assessment made after the adjustment of the micro network confirmed the agreement of the assumed accuracy of the measurement with the one achieved. The a priori standard deviation was selected as 1 . The a posterior standard deviation reached a value of 1.20 after the adjustment of the micro network, being smaller than the limit sample standard deviation $\mathrm{s}_{\mathrm{M}}=1.21$ calculated according to (4).

\subsection{Computation of the detailed survey points from the measurement onto the individual targets}

To compute the coordinates of the detailed survey points (1-10) from the measurement onto the individual targets, the coordinates of the station points (4001-4003) and the points of the base measuring Bala rod (101 and 102) were adopted from the results of the adjustment. The computations were again made in the Gama programme (Čepek, 2012) where only the orientation shift from the station was adjusted. The measurement of two other station points and the points of the base measuring Bala rod were used for orientation. The coordinates of the detailed survey points were computed separately for each target and for each station. The standard deviations in the position of the resultant coordinates of the detailed survey points achieve values of approx. $1 \mathrm{~mm}$.

The coordinates of both foils were computed for the rod target with two foils, and the coordinates of the detailed survey points were additionally computed using the parametric equation of a straight line.

\section{COMPARISON OF THE REFLECTIVE TARGETS}

Individual reflective targets were used to determine the coordinates of the survey points; the coordinates were compared with the reference coordinates, and the standard deviations were calculated from the differences.

Since the target with a collimator should particularly enhance the measurement of distances, the directly measured distances were also compared with the distances computed from the reference coordinates. For the rod target with two foils, the distances computed from the coordinates of the detailed measurement were compared against the distances computed from the reference coordinates.

In comparing the individual reflective targets, the adjusted reference coordinates and the distances computed from them are considered actual (real) values. The differences between these real values and the values obtained from the individual measurements may be considered real errors. The accuracy rate of the individual methods from the sample data sets is characterised by the standard deviation of the measurement identified from the formula:

$$
s=\sqrt{\frac{\left[\varepsilon^{2}\right]}{n}},
$$

where $\varepsilon$ are real errors, and $n$ is the number of errors (Štroner, Hampacher, 2011).

To allow for a more objective accuracy assessment, 95\% reliability intervals are added to the standard deviations. Assuming that experimental random samples come from the normal probability distribution, it holds true for the $95 \%$ reliability interval that

$$
P\left(\sqrt{\frac{n \cdot s^{2}}{\chi_{1-\frac{\alpha}{2},(n)}^{2}}} \leq \sigma \leq \sqrt{\frac{n \cdot s^{2}}{\chi_{\frac{\alpha}{2},(n)}^{2}}}\right)=1-\alpha=0.95,
$$

where $1-\alpha$ is the reliability coefficient; $\mathrm{n}$ is the range of a random sample; $s$ is the standard deviation of a measurement; and $\chi_{1-\alpha / 2,(\mathrm{n})}^{2}$ (or $\chi_{a / 2,(n)}^{2}$ respectively) is the value of the $\chi^{2}$ distribution with $n$ degrees of freedom.

The standard deviation for each reflective target was calculated by (7), and their confidence intervals according to (8) and used together with the number of errors $n$, are given in Tab. 3 for comparing the coordinates of the spatial variations in Tab. 4 for a comparison of the lengths. 


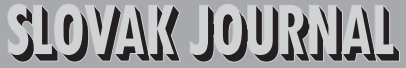 \\ 1) 5

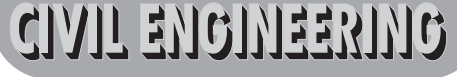

Vol. XXI, 2013, No. 2, $29-40$

Tab. 3 Standard deviations calculated from a comparison of the spatial coordinates.

\begin{tabular}{|c|c|c|c|c|c|}
\hline Type of target & $\begin{array}{c}\text { Target with } \\
\text { collimator (rotated) }\end{array}$ & $\begin{array}{c}\text { Target with } \\
\text { collimator } \\
\text { (non-rotated) }\end{array}$ & $\begin{array}{c}\text { Reflective sheet } \\
\text { target }\end{array}$ & Leica mini prism & $\begin{array}{c}\text { Rod with two } \\
\text { reflective foils }\end{array}$ \\
\hline Standard deviation $[\mathrm{mm}]$ & 0.60 & 2.31 & 0.58 & 0.84 & 0.76 \\
\hline Reliability interval $[\mathrm{mm}]$ & $(0.47 ; 0.82)$ & $(1.81 ; 3.19)$ & $(0.46 ; 0.78)$ & $(0.62 ; 1.30)$ & $(0.52 ; 1.39)$ \\
\hline$n$ & 25 & 25 & 30 & 15 & 9 \\
\hline
\end{tabular}

Tab. 4 Standard deviations calculated from a comparison of the distances.

\begin{tabular}{|c|c|c|c|c|c|}
\hline Type of target & $\begin{array}{c}\text { Target with } \\
\text { collimator } \\
\text { (rotated) }\end{array}$ & $\begin{array}{c}\text { Target with } \\
\text { collimator } \\
\text { (non-rotated) }\end{array}$ & $\begin{array}{c}\text { Reflective sheet } \\
\text { target }\end{array}$ & Leica mini prism & $\begin{array}{c}\text { Rod with two } \\
\text { reflective foils }\end{array}$ \\
\hline Standard deviation $[\mathrm{mm}]$ & 0.58 & 2.29 & 0.57 & 0.42 & 0.62 \\
\hline Reliability interval $[\mathrm{mm}]$ & $(0.45 ; 0.80)$ & $(1.80 ; 3.17)$ & $(0.45 ; 0.76)$ & $(0.31 ; 0.65)$ & $(0.42 ; 1.13)$ \\
\hline$n$ & 25 & 25 & 30 & 15 & 9 \\
\hline
\end{tabular}

According to the size of the standard deviations in Tables 3 and 4, it can be argued that all the reflective targets are comparably accurate for determining the sizes and shapes of steel structures. When comparing the results of the measurements on the target, using a collimator without rotation confirmed that negligent rotation or rotation without checking can cause errors of several millimeters.

The big difference for the Leica mini prism between Tables 3 and 4 is given by the difficult targeting due to the short distance and thus bigger errors in the angle measurement.

\section{TEST MEASUREMENTS WITH DIFFERENT TYPES OF DISTANCE METERS}

The testing aimed at the verification of the suitability of the reflective targets involved the Trimble S6 HP instrument, which possesses a very narrow effective spot of the distance meter (ca $14 \mathrm{~mm}$ in diameter for a distance of $10 \mathrm{~m}$ ) as was experimentally verified in the diploma thesis by Ing. B. Kaanová (Kaanová, 2012). This fact dramatically affects the results achieved, especially for

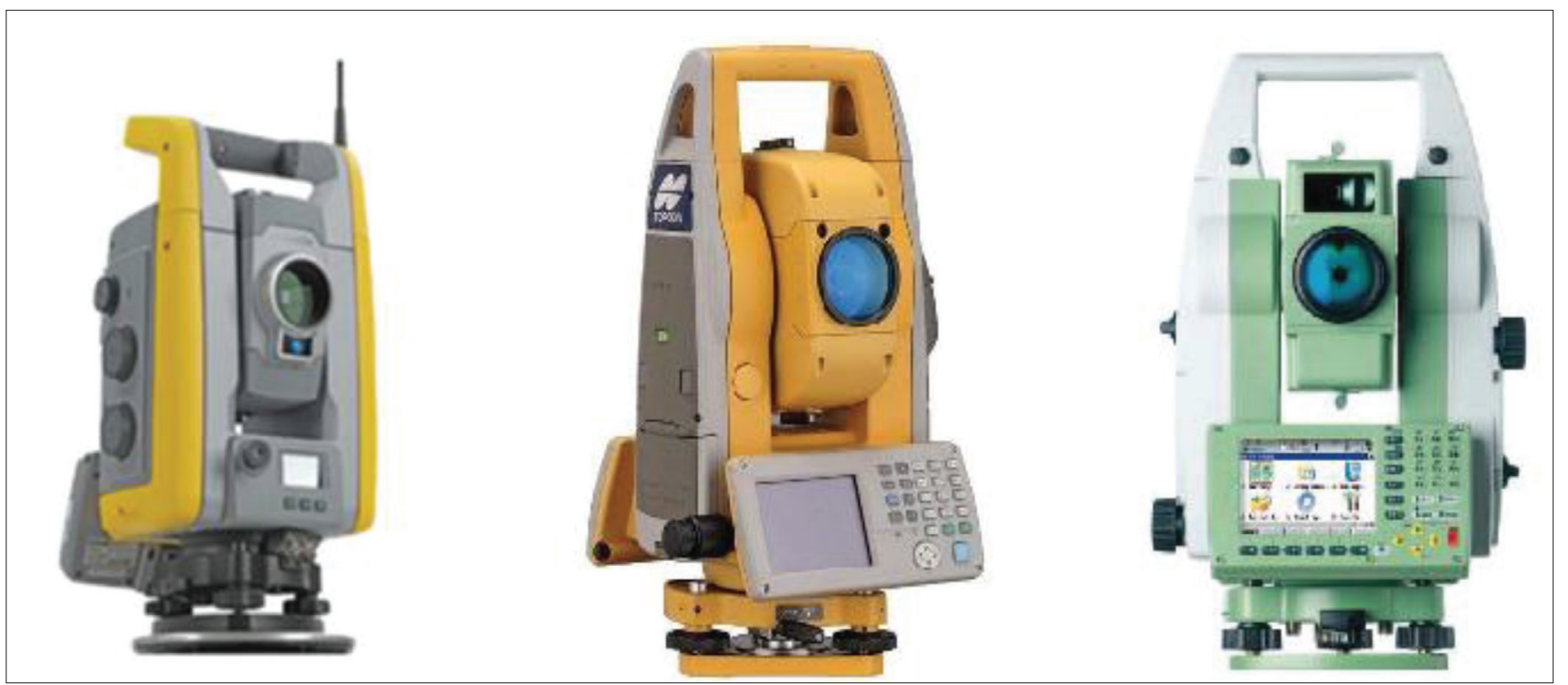

Fig. 10 Trimble S6 HP, Topcon GPT-7501 and Leica TS1202 total stations. 
Vol. XXI, 2013, No. 2, $29-40$

Tab. 5 The size of the effective spots of the distance meters for a distance of $10 \mathrm{~m}$ (Kaanová, 2012).

\begin{tabular}{|c|c|c|c|}
\hline Instrument & Distance meter type & $\sigma_{D}($ ČSN ISO 17123, 2005) & Spot size \\
\hline Trimble S6 HP & phase & $1 \mathrm{~mm}+1 \mathrm{ppm} \mathrm{D}$ & $\varnothing 14 \mathrm{~mm}$ \\
\hline Topcon GPT-7501 & pulse & $2 \mathrm{~mm}+2 \mathrm{ppm} \mathrm{D}$ & $\varnothing 42 \mathrm{~mm}$ \\
\hline Leica TS1202 & phase & $1 \mathrm{~mm}+1.5 \mathrm{ppm} \mathrm{D}$ & $30 \mathrm{~mm} \times 20 \mathrm{~mm}$ \\
\hline
\end{tabular}

a separately attached reflective foil and targeting practically directly onto a point marked in this way, since a "small" spot significantly limits the effect of the erroneous turning of the foil. For this reason, a new testing project using instruments with distance meters possessing a standard-size effective spot was designed to verify the universality of a target with a collimator. In addition to the Trimble S6 HP instrument, the Topcon GPT-7501 and the Leica TC1202 instruments were used (Fig. 10), which serve as standard devices in engineering surveying applications and whose effective spot size is identified according to (Kaanová, 2012) (see Tab. 5). As previous testing had confirmed the suitability of all the reflective targets for the measurement of steel structures, all the targets allowing for the direct measurement of distances, i.e., a reflective mini prism, a separate reflective foil, and a new target with a reflective target plate and a mechanical collimator, were chosen for further testing.

The testing objective was to obtain standard deviations from a comparison of the directly measured lengths and lengths calculated from the reference coordinates.

\subsection{Reference network}

A new reference network was built for the testing measurements with different instruments in the Special Geodesy Laboratory in Building $\mathrm{C}$ of the Faculty of Civil Engineering, CTU in Prague (Fig. 11). Sixteen points stabilised by stickers with a cross (Fig. 7), 6 points (A1-A6) stabilised by black and white square targets $(15 \times 15$ $\mathrm{cm}$ ), and 6 points (B1-B6) stabilised by ground control targets for laser scanning (Fig. 12) were designed in the laboratory. The points were distributed on the floor and on the walls at various heights so that the determination of the spatial coordinates of a station from an arbitrary location in the laboratory would be allowed by using the resection method onto selected points and, at the same time, there would still remain a sufficient number of other points available for various testing measurements.

The new network was surveyed in the same way as the reference micro network described in paragraph 3.1. Four stations (40014004) stabilised by tripods were selected in the laboratory. Besides, a tripod with a standardised 2-metre Bala subtense bar selected for the identification of the network dimensions was placed as far from the stations as possible. The Trimble S6 HP instrument was chosen to survey the network. From each station, the measurement of the horizontal directions and zenith angles in the two groups was performed on all the points on the walls and on both ends of the subtense bar, plus the measurement of the horizontal directions, zenith angles and slope distances in the two groups onto the other station points. Stations 4001 and 4002 were also used for the measurement on 3 points on the floor. The selected target on the station was a fixture with a foil, which ensures precise centering and a height identical to that of the axis of rotation of the telescope of the Trimble S6 HP instrument (Fig. 9).

\subsection{Calculating the reference network}

The coordinates of the points in the network were calculated by adjustment using the least squares method in the Gama programme (Čepek, 2012). Due to the very short sightline lengths (aprox. 4 $\mathrm{m}$ ), the standard deviations of the measurement of the horizontal directions and zenith angles for group 1 were selected as 2 mgon, and the standard deviation for the measurement of the lengths was selected as $1 \mathrm{~mm}$ (Trimble S6 HP) as declared by the manufacturer of the instrument.

A total of 126 horizontal directions, 126 zenith angles and 12 slope distances were measured in the network from 4 standpoints. The number of unknown quantities was identified as 101 (XYZ coordinates of 32 points, the $\mathrm{Z}$ coordinate of one point of the subtense bar, and 4 orientation shifts). One outlying measurement (horizontal direction) was identified in 163 redundant measurements; therefore, 263 observations were used for the calculations. Fixed $X Y Z$ coordinates $(X=500 \mathrm{~m} ; Y=100 \mathrm{~m} ; Z=100 \mathrm{~m})$ were entered for point 101 (left end of the Bala subtense rod), and fixed $X Y$ coordinates $(X=500 \mathrm{~m} ; \mathrm{Y}=102 \mathrm{~m})$ were entered for point 102 (right end of the Bala subtense rod).

The assessment performed after the network adjustment confirmed the agreement of the assumed and measurement accuracy achieved. The a priori standard deviation was selected as a value of 1 . The a posteriori standard deviation reached a value of 0.94 after the network adjustment, being smaller than the limit value of the sample standard deviation $\mathrm{s}_{\mathrm{M}}=1.11$ calculated according to (Štroner, Hampacher, 2011). The following values of the standard deviations of the position were selected for the description of the accuracy of the results:

- The maximum standard deviation of the position is $0.8 \mathrm{~mm}$.

- The minimum standard deviation of the position is $0.2 \mathrm{~mm}$.

- The mean standard deviation of the position is $0.5 \mathrm{~mm}$. 


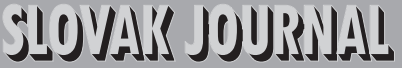 \\ 1) $)^{5}$

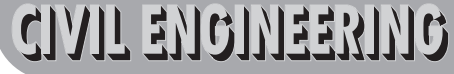

Vol. XXI, 2013, No. 2, $29-40$

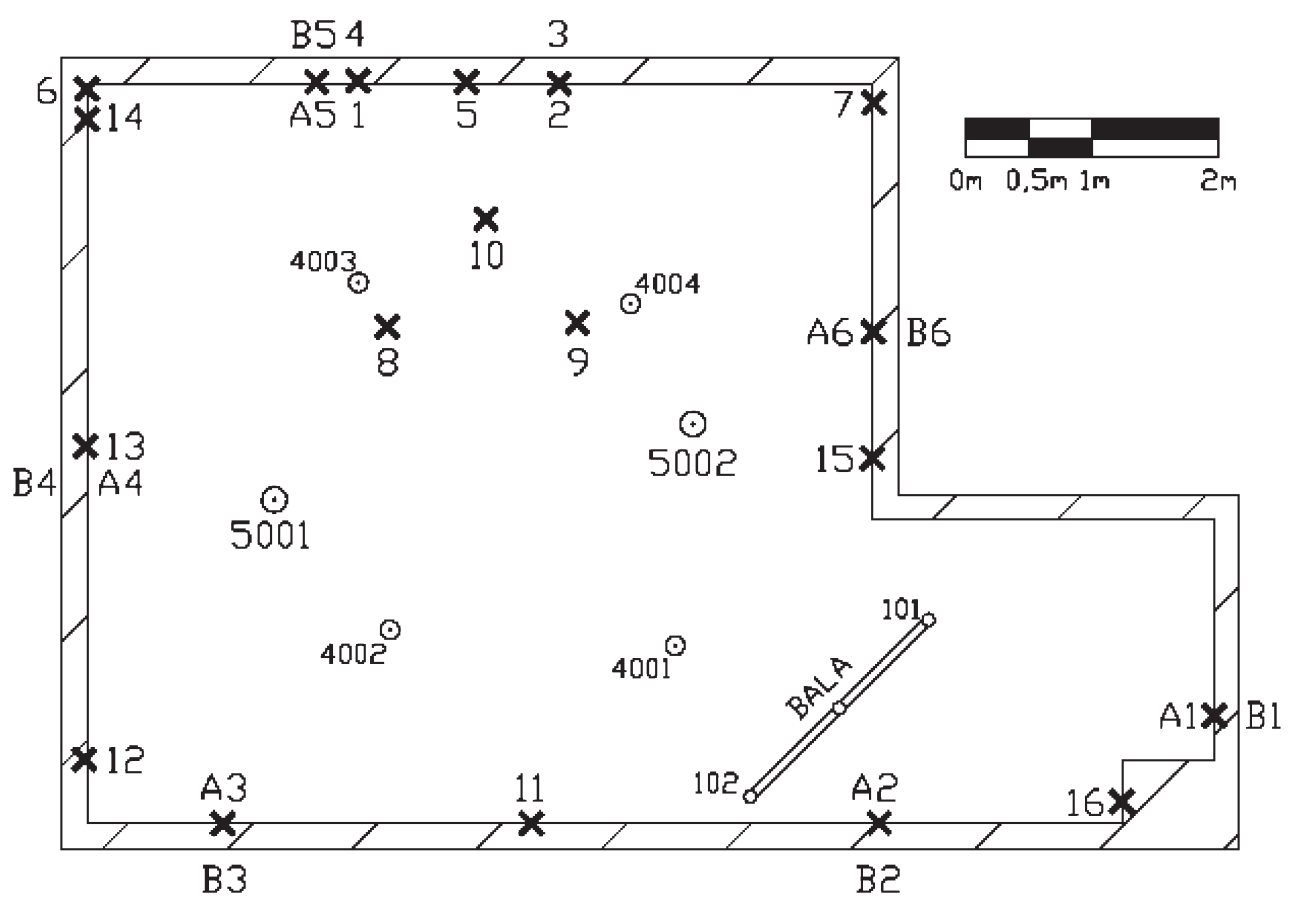

Fig. 11 The laboratory network scheme.

\subsection{Testing measurement with three total stations}

Two stations (points 5001 and 5002 in Fig. 11), whose coordinates had been calculated by the resection method from the horizontal directions and zenith angles measured in group 1 onto 6 points (points A1 to A6), were selected for each total station during the testing measurements. The calculation was made using the Gama programme (Čepek, 2012), and the resultant standard deviations of the position of the stations achieved ca $0.1 \mathrm{~mm}$.

The measurement of the lengths onto 5 points $(5,10,11,14,16)$ in 5 groups was made from both stations onto each tested target.

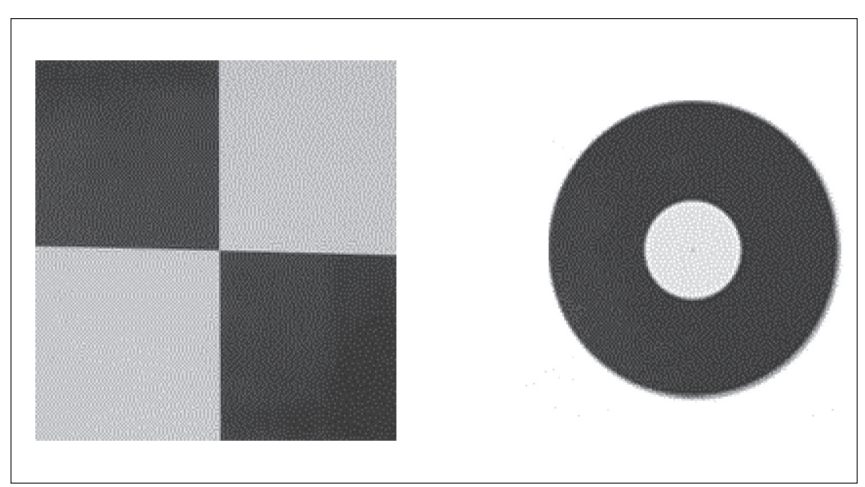

Fig. 12 Points A1-A6 and points B1-B6.
These points were selected to simulate the different configurations of the measured points. In this way, a total of 50 values was obtained for each target and for each respective total station. This number is identified based on the consideration of the value of the standard deviation of the sample standard deviation $\sigma_{Z}$, which is defined by the formula:

$$
\sigma_{Z}=\frac{\sigma}{\sqrt{2 \cdot(n-1)}}
$$

where $\sigma$ is the standard deviation expressing the accuracy of the length measurement. Based on a preset condition that the standard deviation $\sigma_{Z}$ may reach the maximum of $10 \%$ of the value of the standard deviation $\sigma$, the range of the random sample is identified as:

$$
\sigma \cdot \frac{1}{\sqrt{2 \cdot(n-1)}}=0.1 \cdot \sigma \Rightarrow n=51 \text {. }
$$

The Trimble S6 HP and the Leica TS1202 total stations were used for double measurement during the measurement on a new reflective target with a collimator. One measurement was on the centre of the foil, and the other on the lower edge of the foil (closest to the tip); both measurements were performed after separate levellings of the fixture. The purpose of this procedure was to identify whether better measurement results may be obtained during a measurement closer 
Vol. XXI, 2013, No. 2, $29-40$

Tab. 6 Standard deviations of length measurements on reflective targets.

\begin{tabular}{|c|c|c|c|c|c|}
\hline \multicolumn{2}{|c|}{ Type of target / Instrument } & Trimble S6 HP & $\begin{array}{c}\text { Topcon } \\
\text { GPT-7501 }\end{array}$ & $\begin{array}{c}\text { Leica TS1202 } \\
\text { (prism mode) }\end{array}$ & $\begin{array}{c}\text { Leica TS1202 (foil } \\
\text { mode) }\end{array}$ \\
\hline \multirow{2}{*}{$\begin{array}{c}\text { Target with a collimator } \\
\text { (centre) }\end{array}$} & Standard deviation [mm] & 0.69 & 1.22 & 0.89 & 0.89 \\
\cline { 2 - 6 } & Reliability interval [mm] & $(0.58 ; 0.86)$ & $(1.02 ; 1.52)$ & $(0.74 ; 1.10)$ & $(0.75 ; 1.11)$ \\
\hline \multirow{2}{*}{$\begin{array}{c}\text { Target with a collimator } \\
\text { (lower part) }\end{array}$} & Standard deviation [mm] & 0.51 & - & 1.08 & 1.06 \\
\cline { 2 - 6 } & Reliability interval [mm] & $(0.42 ; 0.63)$ & - & $(0.90 ; 1.34)$ & $(0.88 ; 1.31)$ \\
\hline \multirow{2}{*}{\begin{tabular}{c} 
Leica mini prism \\
\cline { 2 - 6 } Separate reflective foil
\end{tabular}} & Standard deviation [mm] & 0.81 & 1.62 & 0.95 & 0.89 \\
\cline { 2 - 6 } & Reliability interval [mm] & $(0.68 ; 1.01)$ & $(1.35 ; 2.01)$ & $(0.80 ; 1.19)$ & $(0.75 ; 1.11)$ \\
\hline
\end{tabular}

to the fixture tip, as the closer to the tip we target, the smaller the error due to non-levelling should be.

The Leica TS1202 total station was used twice to measure with a different setting-up. First, the distance meter was set up to measure on a reflective prism, and then the distance meter was set up to measure on a reflective foil. This procedure was selected on the basis of experience with this type of instrument, where the distance meter behaves as if it were prismless in the measurement mode on a reflective foil, being able to measure distances of up to ca $50 \mathrm{~m}$ even on areas without reflective elements. The double measurement was, therefore, made to check whether the results in the setting-up of the measurement on a foil are not distorted by undesirable reflections.

\subsection{Processing of measurements}

Distances that would be considered actual (real) values in subsequent calculations were calculated from the reference coordinates for the respective stations and measured points. The differences between these real lengths and the lengths obtained from the measurements on the reflective targets are considered real errors.

\subsubsection{Elimination of outliers}

In repetitive measurements of lengths by a total station, a potential sporadic effect of large measurement errors is assumed (caused, e.g., by a sudden variation in the conditions of the environment or by an operator error). This effect leads to the appearance of outlying values in random samples obtained by the measurement. It is desirable to eliminate outliers during the data processing, thus ensuring greater objectivity of the results of the data assessed.

The statistical testing was done using the Grubbs corrections test with an unknown basic standard deviation consisting of a comparison of the individual measurement corrections with the limit correction value (Štroner, Hampacher, 2011). All 15 random samples were subjected to testing at the significance level of $5 \%$. No outliers were detected in any of the samples.

\subsubsection{Verification of the normality of the random samples}

It is assumed that experimental random samples obtained by repetitive measurements come from a basic set with a normal probability distribution. To confirm this hypothesis, the data were subjected to testing against the normality criteria by means of empirical moments (Štroner, Hampacher, 2011). Tests for asymmetric distributions and tests for the distribution excess criterion were performed. The testing at the significance level of $5 \%$ led to the conclusion that all the data are roughly normally distributed and fit for further processing.

\subsection{Comparison of targets}

The standard deviation expressing the accuracy of the length measurements was calculated for each type of reflective target and each total station according to (7). The values are computed from the differences between the computed and measured distances. The standard deviations listed in Tab. 6 were fitted with reliability intervals additionally calculated according to (8).

Based on the magnitude of the standard deviations of the length measurements listed in Tab. 6, it can be stated that the new target with a reflective foil and a mechanical collimator is the most suitable option for the measurement of lengths on points of steel structures. The magnitudes of the standard deviations of the length measurements on a target with a collimator and on a mini prism are roughly comparable, but compared to the other ones, the standard deviation of the length measurements on a separate reflective foil is greater, which may, above all, be caused by the impossibility of turning it and by the larger effective spot of the distance meter. 


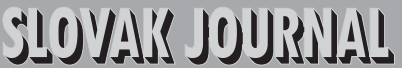 \\ 1) 5

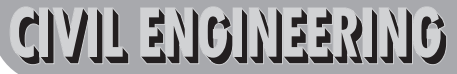

Vol. XXI, 2013, No. 2, $29-40$

When comparing the results of the Leica TS1202 instrument in the prism mode to the foil mode, it is evident that different distance meter set-ups do not cause any differences in the results.

\section{CONCLUSION}

The testing measurements and the calculation of the coordinates verified the suitability and comparative accuracy of all the reflective targets used for the determination of the dimensions and shapes of the steel structures. The newly developed and tested target plate with a reflective foil and a mechanical collimator manifested a high degree of accuracy and usability, its major significant property being the option of a visual check and correction of correctly turning it. The comparison of the results of the measurements on a target without turning by means of a collimator confirmed that careless turning or turning without checking may cause large errors of up to several millimetres.

The testing with different total stations which have distance meters with effective spots of different sizes proved that a target with a collimator shows the lowest values of the standard deviations of length measurements and confirmed the significance of the controlled turning of reflective targets. In targeting on the centre of the new fixture, the target is suitable for any total station, and it may become a valuable accessory or a replacement for targets commonly used in mechanical engineering measurements.

The article was written with support from the internal grant No. SGS13 "Optimization of the acquisition and processing of $3 D$ data for the needs of engineering surveying".

\section{REFERENCES}

ČSN ISO 17123-3, (2005) Optika a optické přistroje - Terénní postupy pro zkoušení geodetických a měrických př́strojů - Část 3. Teodolity (Optics and optical instruments - Field procedures for testing geodetic and surveying instruments - Part 3: Theodolites). Prague: Czech Standards Institute. 28 pp.

ČSN ISO 17123-4, (2005) Optika a optické př̀stroje - Terénní postupy pro zkoušeni geodetických a měrických přsistroju - Část 4: Elektrooptické dálkoměry (Optics and optical instruments Field procedures for testing geodetic and surveying instruments - Part 4: Electro-optical distance meters (EDM instruments)). Prague: Czech Standards Institute. $24 \mathrm{pp}$.

Čepek, A. (2012) GNU Gama 1.12 - Adjustment in Geodetic Networks. [online]. [cit. 2012-09-07]. Available at: http://www.gnu. org/software/gama/manual/gama.html.
Štroner, M. - Hampacher, M. (2011) Zpracování a analýza měrení $v$ inženýrské geodézii (Processing and Analysis of Measurements in Engineering Surveying). $1^{\text {st }}$ edition. Prague: CTU Publishing House. 313 pp., ISBN 978-80-01-04900-6.

Kaanová, B. (2012) Experimentálni určeni tvaru a rozměru efektivní stopy dálkomèru (Experimental Determination of the Shape and Dimension of the Effective Spot of an Electronic Distance Meter). Diploma thesis, CTU.

Prokop, J. (2009) Surveying Tasks on Offshore Oil Installations. Proceedings of the $45^{\text {th }}$ Geodetic Information Days, Brno, Czech Republic, ECON Publishing, Ltd. (in Czech), ECON Publishing s.r.o., Brno, Czech Republic, ISBN 978-80-8643337-0, pp. 123-129. 